Tropical Journal of Pharmaceutical Research March 2020; 19 (3): 667-672

ISSN: $1596-5996$ (print); 1596-9827 (electronic)

(C) Pharmacotherapy Group, Faculty of Pharmacy, University of Benin, Benin City, 300001 Nigeria.

Available online at http://www.tjpr.org

Review Article

http://dx.doi.org/10.4314/tjpr.v19i3.30

Review Article

\title{
Exosomes: Salivary Biomarkers?
}

\author{
Zeeshan Qamar ${ }^{1,2 *}$, Fayez Hussain Niazi ${ }^{3}$, Syed Bilal Tanveer ${ }^{4}$, Tayyaba \\ Zeeshan ${ }^{5}$ \\ ${ }^{1}$ Department of Oral and Maxillofacial Surgery, Faculty of Dentistry, Riyadh Em University, Riyadh, Saudi Arabia, ${ }^{2}$ Department \\ of Oral Biology, Faculty of Dentistry, Liaquat College of Medicine and Dentistry, Karachi, Pakistan, ${ }^{3}$ Department of Restorative \\ and Prosthetic Dentistry, Dar Al Uloom University, ${ }^{4}$ Department of Preventive Dental Sciences, College of Dentistry, Dar al \\ uloom University, Riyadh, Saudi Arabia, ${ }^{5}$ Department of Oral Biology and Biomedical Sciences, Faculty of Dentistry, University \\ Malaya, Kuala Lumpur, Malaysia
}

*For correspondence: Email: zeeshan.qamar@riyadh.edu.sa; Tel: 00966-(0)53- 8672265

Sent for review: 9 November 2019

Revised accepted: 26 February 2020

\begin{abstract}
Saliva is a bio-fluid considered similar to blood in that it contains various DNAs, RNAs and proteins. Therefore, it is a fluid with diagnostic potential. In recent time, exosomes are emerging as nano-vesicles which enhance intra-cellular communication. Exosomal content, which is dependent on the cell of origin, reflects physiological status of cells. Exosomes have potentials for use as biomarkers for variant diseases, based on their stability and availability in various body fluids. Current studies have proposed the role of exosomes as immuno-modulators in the etiology of auto-immune diseases and cancers. The present study focused on the role of exosomes as biomarkers and their therapeutic potentials in particular diseases related to the oral cavity.
\end{abstract}

Keywords: Exosomes, Auto-immune, Biomarkers, Saliva, Diagnosis

\begin{abstract}
This is an Open Access article that uses a fund-ing model which does not charge readers or their institutions for access and distributed under the terms of the Creative Commons Attribution License (http://creativecommons.org/licenses/by/4.0) and the Budapest Open Access Initiative (http://www.budapestopenaccessinitiative.org/read), which permit unrestricted use, distribution, and reproduction in any medium, provided the original work is properly credited.
\end{abstract}

Tropical Journal of Pharmaceutical Research is indexed by Science Citation Index (SciSearch), Scopus, International Pharmaceutical Abstract, Chemical Abstracts, Embase, Index Copernicus, EBSCO, African Index Medicus, JournalSeek, Journal Citation Reports/Science Edition, Directory of Open Access Journals (DOAJ), African Journal Online, Bioline International, Open-J-Gate and Pharmacy Abstracts

\section{INTRODUCTION}

Human saliva is a clear and complex oral fluid which tends to coat the oral tissues. The saliva originates from different glandular and nonglandular secretions. The glandular secretions are produced from salivary glands, whereas the non-glandular secretions include crevicular fluids rich in oral microorganisms and host cells [1]. The salivary glands in human body are classified according to their sizes as major- and minor glands. The first category of major glands includes the paired parotid, and submandibular and sublingual glands [1]. The normal $\mathrm{pH}$ of human saliva ranges from 6.0 to 7.0 , indicating that if it is slightly acidic or neutral. However, the salivary $\mathrm{pH}$ can vary in large range from 5.3 to 7.8 depending on its flow rate, lowest $\mathrm{pH}$ at low flow rate whereas higher values at peak saliva flow [3]. The amount of hydrogen bicarbonate in saliva determines salivary $\mathrm{pH}$ and buffering capacity [4].

Saliva is $99 \%$ watery fluid, but becomes viscoelastic (thick and sticky) depending on the amount of protein content [2-4]. The average flow rate of unstimulated saliva in normal, healthy individuals is about $600 \mathrm{~mL}$ per day [5]. In a state of stimulation such as during meals, saliva secreted by parotid glands is about 60 - 
$65 \%$ of whole salivary volume, with $20-30 \%$ from submandibular and sublingual glands [6], and approximately $10 \%$ from minor salivary glands. In the resting state, the situation is different: approximately $50 \%$ of total saliva is secreted by submandibular glands $[6,7]$.

The saliva has a capability to provide links to local- and systemic diseases, since it contains molecules of RNA, DNA, salivary proteins, and metabolites, as well as microorganisms. Any alteration in the molecular content is considered as biomarkers for detection and monitoring of diseases [8].

Exosomes are bi-layer, lipid-enclosed nanovesicles of $40-100 \mathrm{~nm}$ in diameter [9]. They are formed by endosomal endocytosis, resulting in multiple vesicular bodies (MVBs) containing intra-luminal vesicles (ILV). Being endosomal in origin, they act as carriers for fusion proteins, MVB biogenesis proteins, heat shock proteins, lipid-related proteins, integrins, phospholipases and tetraspanins [10]. Depending on the cells of origination, exosomes also carry nucleic acids, lipids and the proteins [11]. Different cells like hematopoietic cells, cells of intestinal epithelium, adipocytes, tumor-like cells, fibroblasts and Schwann cells secrete various exosomes in body fluids (plasma, urine human milk and cerebrospinal fluid) [12]. Willms et al [13] have reported that inconsistent exosomal subpopulations have various special effects on the recipients' cell gene expressions. In particular, the transporter endosomal sorting complex (ESC) is composed of proteins active in budding endosomal membranes [14]. These proteins are marked liable for sorting and biosynthesizing of MVB involved in exosome formation [14].

The exosomes tend to fuse with the cellular membrane of the targeted cells, prior to emptying their contents in the cytoplasm, followed by endocytosis. The exosomes enter via various pathways such as macro-pinocytosis, endocytosis dependent on the clathrin-dynamincaveolae, and the phagocytosis relying on the recipient cells [15]. These exosomes are thought to be responsible for cellular communication, regulation of gene expression, alteration in cellular signaling, and functional modification of target cells [16]. Alterations in the molecular contents of exosomes have been observed during pathophysiological, cellular or tissue changes. Thus, exosomes are expected to act as diagnostic markers.

Moreover, exosomes are involved in the pathogenesis and progression of diseases such as metastasis of cancer, neural degradation, cardiac hypertrophy, renal and auto-immune disorders [17]. Recent studies have shown the diverse potential of exosomes such as induction of immunity for cancer cells, bacterial infections, evasion of host immunity, and reduction of inflammation, indicating their potential as smart therapeutic-vehicles for various diseases [18]. The major purpose of this review was to present contemporary and updated information regarding the use of exosomes in systemic auto-immune diseases with oral manifestations, as well as its biomarker and remedial potential

\section{Potential role of exosomes in oral manifestation of auto-immune disorders}

Exosomes are involved in various processes such as immuno-modulation and immuneregulation, and they have potential for intercellular communication by transporting regulatory molecules to adjacent and the distant cells [19]. Various investigators have reported the potential of exosomes for direct and indirect activation of $\mathrm{T}$ cells by dendritic cells [20]. Exosomes tend to arbitrate transportation of antigens directly by transportation of major histocompatibility complex and co-stimulatory molecules [21]. Indirectly, exosomes help in transfer of antigens to antigen presenting cells [22]. Mature dendritic cells which give rise to exosomes have immune-stimulatory effects, whereas immature dendritic cell exosomes (DCex) have immune-suppressive potential [23]. Mature DCex, in contrast to those produced by immature DCex, have extensive number of costimulatory and adhesive ligands expressing immune-suppressive ligands [tumor growth factor- $\beta$ (TGF- $\beta$ ), NKG2D, and galectin-9]. Moreover, they tend to secrete death ligands e.g. CD95L [24].

\section{Exosomes in autoimmune salivary gland disorder}

Exosomes have been studied in Sjogren's syndrome (SS), an autoimmune salivary gland disorder which was first described as an autoimmune condition characterized with dry mouth and dry eyes in 1933 by a physician, Henrik Sjogren [25]. A chronic, multi-system autoimmune disease can be identified from periepithelial infiltrates of lymphocytes which lead to inflammation of the exocrine glands. The autoantigens linked to SS and other auto-immune disorders are Anti-Ro (SSA)/ La (SSB). Kapsogeorgou and co-workers [26] have reported secretion of Ro/SSA, La/SSB and Sm from non-neoplastic salivary gland epithelial cells (SGECs), showing auto-immune exosomal regulatory response to $S S$. Other than the 
transportation of auto-antigens, exosomes tend to transport conserved, small, non-coding RNA tangled in post-transcriptional modulation of genes known as microRNA (micRNA). Researchers have reported the effect of micRNA in regulating immune response, and have shown crucial regulatory mechanisms relative to autoimmunity [27]. Gallo and co-workers [28] have reported various micRNAs associated with exosomes in saliva.

Researchers have also reported the isolation of microRNA from the exosomes of parotid gland of patients suffering from primary SS and healthy volunteers [29]. The occurrence of three micRNAs (has-miR-203, has-mir-786-3p and has-mir-574-3p) has been reported, using TaqMan micRNA quantitative amplification. Similar micRNAs have also been observed in the saliva produced by the minor salivary gland and whole saliva in patients suffering from primary SS. It has been reported that micRNA has-mir-786-3p and has-mir-574-3p can be used to identify patients with primary SS, based on salivary gland focus scores [30]. Recently, has-mir-786-3p, a small nucleolar RNA (nuRNA) has been identified as a biomarker for primary SS. In the near future, research on exosomes may lead to a detailed understanding of the etiology and pathogenesis of SS.

Exosomes produced by saliva contain noninvasive diagnostic information regarding the patho-physiological condition of the salivary gland. The micRNA of exosomes are more stable and more impermeable to degeneration in longterm storage and freeze/defrost cycles than the circulating RNAs [31,32]. This is likely due to lipoproteins in the exosomes which protect them from degradation. A false positive result may be observed due to circulating micRNA derived from dead cells or inflammatory cells. The stability of exosomes and their cargo increases the reliability of exosomes as potential biomarkers.

\section{Exosomes in oral lichen planus}

Oral lichen planus is an inflammatory mucosal condition which is idiopathic in origin. Various studies have been conducted on the extraction of exosomal micRNA from whole saliva of individuals suffering from chronic oral lichen planus (OLP), an auto-immune disease. Oral lichen planus (OLP) can be identified from the presence of keratotic/erythematous and ulcerative lesions [33]. Byun and co-workers [33] demonstrated up-regulation of has-miR-4484 in the salivary exosomes of patients with OLP. Thus, has-miR-4484 may be a potential biomarker for OLP. Statistically significant difference in exosomal expression between diseased and healthy individuals makes exosomes attractive biomarkers for OLP. Moreover, micRNAs are linked with variations of cytokine expressions in OLP, indicating its pathogenesis [34].

\section{Salivary exosome as a potential biomarker for oral cancer}

As a first line of defense, saliva contains various enzymes, proteins and immunoglobins. Proteomic analysis has revealed that saliva contains high levels of immunoglobin $A(\lg A)$ with anti-inflammatory effect [35]. The oral squamous cell carcinoma (OSCC) is one of the most widespread oral cancers which accounts for more than $90 \%$ of various cancers in oral region with poor prognosis [36]. It is usually diagnosed at an advanced stage, with more than $50 \%$ of patients presenting with lymph node involvement $[37,38]$. Although many advances have been made in treatment approaches for the cancers, the survival of the patients (less than $50 \%$ ) has not significantly improved [39]. A group of researchers demonstrated differences between exosomal morphology and molecular features of healthy individuals, and those of patients suffering from oral cancer, which led to marker for early diagnosis of malignancy changes in patients with higher risk of cancer [40].

Another group of researchers observed that exosomes derived from the hypoxic cells of OSCC tended to increase migration and invasion in an HIF- $1 \alpha$ and HIF- $2 \alpha$-dependent pattern [41]. The micRNA derived from exosomes of normoxic and hypoxic OCSS cells displayed different expression levels of 108 mic RNA, with micRNA-21 up-regulated significantly in hypoxic OSCC cells. This suggests that hypoxic environment has potential to stimulate tumor cells for production of micRNA-21-enriched exosomes, which in-turn, are delivered to normoxic cells for the promotion of prometastatic behavior. Furthermore, the exosomes rich in micRNA-21 target the phosphate and tensin homolog (PTEN) and protein 4 for programmed cellular death (PDCD4) [42]. Kawakubo-Yasukochi and co-workers [43] reported that highly-invasive OSCC cell exosomes containing micRNA-200c- 3p can lead to a similar type in the non-invasive regions. On salivary profiling analysis 381 proteins have been detected from extracellular vesicles (EVs) of both OSCC and healthy individuals, but only 8 were expressed differently, i.e. alpha-2-macroglobulin, haptoglobin alpha chain, mucin 5B, galectin-3binding protein, immunoglobulin alpha-1 chain $\mathrm{C}$ region, prolactin-inducible protein, pyruvate 
kinase isozymes $\mathrm{M} 1 / \mathrm{M} 2$, and glyceraldehyde-3phosphate dehydrogenase [44].

\section{Therapeutic exosomes}

Besides being biomarkers, exosomes have potential of being therapeutic agents for various diseases. The deterioration of exosomal content is controlled by a biogenic non-synthetic lipid bilayer [45]. Being small and flexible, the exosomes have potential to pass through the membranes and prevent phagocytosis/deterioration by macrophages. Being stable in various biological fluids, exosomes can send their contents to a variety of cells present throughout the body. Exosomes are endogenous vesicles with higher bio-safety than synthetic liposomes [46]. Ohno and group of workers [47] demonstrated suppression of cancer growth in xenografted mice through delivery of tumor-suppressing micRNA via exosomes. Moreover, exosomes with sifRNA can be used for suppression of cancer cells in xenografted mice [48]. Exosomes can be contrived to explicit cancer-specific antigens, which in turn, stimulate anti-tumor immune response [49].

Exosomes can be used as nano-carriers since they exert little or no toxic effects. These endogenous vesicles are used for immunetherapy of various diseases such as rheumatoid arthritis, cancer, multiple sclerosis and inflammatory bowel disease [50]. Munich and coworkers have demonstrated that exosomes derived from the dendritic cells (dexosomes) can stimulate caspase activation and tumor cell apoptosis in a murine model [51]. During initial clinical trials (Phase I) for treatment of melanoma and lung cancer in humans, immune-therapy with dexosome promoted innate, disease stabilization and adaptive immune response, thereby increasing survival of patients [52].

Dexosomes have shown potential for use in the treatment of Alzheimer's disease through delivery of RNA interference (RNAintf) to specific parts of the brain [53]. Kim and co-workers [54] have reported IL-4-containing dexosomes with potent effects on collagen-induced arthritis in a murine model. Furthermore, various studies in murine models have demonstrated that exosomes generated by mesenchymal cells have potential to reduce myocardial ischemia and reperfusion injury [55], enhance neurovascularization [56], and confer protection from acute-tubular injury $[57,58]$. Thus, it can be concluded that exosomes have potential for treatment of various diseases. However, till date, studies on this subject have been limited to animal models.

\section{CONCLUSION}

In healthy individuals, the main function of exosomes is regulation of cellular function and intracellular communication. On the other hand, under abnormal conditions, exosomes increase with severity of illness, invade host immunesystem, and mediate cancer metastasis. Furthermore, due to their availability in various body fluids/cell types, exosomes serve as potent biomarkers for disease diagnosis, pathogenesis and prediction of treatment response. Further research is required to unravel the regulation and effect of exosomes in recipient cells.

\section{DECLARATIONS}

\section{Conflict of interest}

No conflict of interest is associated with this work.

\section{Contribution of authors}

We declare that this work was done by the authors named in this article and all liabilities pertaining to claims relating to the content of this article will be borne by the authors.

\section{Open Access}

This is an Open Access article that uses a funding model which does not charge readers or their institutions for access and distributed under the terms of the Creative Commons Attribution License (http://creativecommons.org/licenses/by/ 4.0) and the Budapest Open Access Initiative (http://www.budapestopenaccessinitiative.org/rea d), which permit unrestricted use, distribution, and reproduction in any medium, provided the original work is properly credited.

\section{REFERENCES}

1. Patel VN, Hoffman MP. Salivary gland development: $A$ template for regeneration. Semin Cell Dev Biol 2014; 25 : 52-60.

2. Cunha-Cruz J, Scott J, Rothen M, Mancl L, Lawhorn T, Brossel K, Berg J. Salivary characteristics and dental caries: evidence from general dental practices. J Am Dent Assoc 2013; 144: 31-40.

3. Kuriakose S, Sundaresan C, Mathai V, Khosla E, Gaffoor FM. A comparative study of salivary buffering capacity, flow rate, resting $\mathrm{pH}$, and salivary Immunoglobulin $A$ in 
children with rampant caries and caries-resistant children. J Indian Soc Pedod Prev Dent 2013; 31: 69-73.

4. Naveen $S$, Asha ML, Shubha G, Bajoria AA, Jose $A A$. Salivary Flow Rate, $\mathrm{pH}$ and Buffering Capacity in Pregnant and Non-Pregnant Women-A Comparative Study. JMED Res 2014; 2014: 1-8.

5. Watanabe $S$, Dawes $C$. The effects of different foods and concentrations of citric acid on the flow rate of whole saliva in man. Arch Oral Biol 1988; 33: 1-5.

6. Dijkema T. Salivary gland sparing radiotherapy. Diss. Utrecht University 2013; 1-268.

7. Dawes C. Rhythms in salivary flow rate and composition. Int J Chronobiol 1974; 2: 253-279.

8. Lee JM, Garon E, Wong DT. Salivary diagnostics. Orthod Craniofac Res 2009; 12: 206-211.

9. Kooijmans $S A$, Vader $P$, van Dommelen SM, van Solinge WW, Schiffelers RM. Exosome mimetics: a novel class of drug delivery systems. Int J Nanomedicine 2012; 7: 1525-1541.

10. Ung TH, Madsen HJ, Hellwinkel JE, Lencioni AM, Graner MW. Exosome proteomics reveals transcriptional regulator proteins with potential to mediate downstream pathways. Cancer Sci 2014; 105: 1384-1392.

11. Abramowicz A, Widlak P, Pietrowska M. Proteomic analysis of exosomal cargo: the challenge of high purity vesicle isolation. Mol Biosyst 2016; 12: 1407-1419.

12. Madison MN, Roller RJ, Okeoma CM. Human semen contains exosomes with potent anti-HIV-1 activity. Retrovirology 2014; 11: 102-117.

13. Willms E, Johansson HJ, Mager I, Lee $Y$, Blomberg KE, Sadik M, Alaarg A, Smith CE, Lehtio J, Andaloussi SE, Wood MJ. Cells release subpopulations of exosomes with distinct molecular and biological properties. Sci Rep 2016; 6: 22519-22531.

14. Hanson PI, Cashikar A. Multivesicular body morphogenesis. AnnuRev Cell Dev Biol 2012; 28: 337362.

15. Tian $T$, Zhu $Y L$, Zhou $Y Y$, Liang GF, Wang $Y Y, H u F H$, Xiao ZD. Exosome uptake through clathrin-mediated endocytosis and macropinocytosis and mediating miR21 delivery. J Biol Chem 2014; 289: 22258-22267.

16. Thery C, Zitvogel L, Amigorena S. Exosomes: composition, biogenesis and function. Nat Rev Immunol 2002; 2: 569-579.

17. Ailawadi S, Wang X, Gu H, Fan GC. Pathologic function and therapeutic potential of exosomes in cardiovascular disease. Biochim Biophys Acta 2015; 1852: 1-11.

18. Song J, Huang J, Chen $X$, Teng $X$, Song $Z$, Xing $Y$, Wang $M$, Chen K, Wang Z, Yang $P$, Hu S. Donor-derived exosomes induce specific regulatory $T$ cells to suppress immune inflammation in the allograft heart. Sci Rep 2016; 7: 20077-20087.

19. Greening DW, Gopal SK, Xu R, Simpson RJ, Chen W. Exosomes and their roles in immune regulation and cancer. Sem Cell Dev Biol 2015; 40: 72-81.

20. Admyre C, Johansson SM, Paulie S, Gabrielsson S. Direct exosome stimulation of peripheral human $T$ cells detected by ELISPOT. EurJ Immunol 2006; 36: 17721781.

21. Muntasell A, Berger AC, Roche PA. T cell-induced secretion of MHC class II-peptide complexes on $B$ cell exosomes. EMBO J 2007; 26: 4263-4272.

22. Martin RK, Brooks KB, Henningsson $F$, Heyman $B$, Conrad $\mathrm{DH}$. Antigen transfer from exosomes to dendritic cells as an explanation for the immune enhancement seen by IgE immune complexes. PloS one 2014; 9: 1-6.

23. Bu N, Wu HQ, Zhang GL, Zhan SQ, Zhang R, Fan QY, Li $Y L$, Zhai YF, Ren HW. Immature dendritic cell exosomes suppress experimental autoimmune myasthenia gravis. J Neuroimmunol 2015; 285: 71-75.

24. Hwang I. Cell-cell communication via extracellular membrane vesicles and its role in the immune response. Mol Cells 2013; 36: 105-111.

25. Sjogren H. Zur Kenntnis der Kerato-conjunctivitis Sicca (Keratitis Filiformis bei Hypofunction der tranendrusen). Acta Ophthalmol Copenh 1933; 11: 1-151.

26. Kapsogeorgou EK, Abu-Helu RF, Moutsopoulos HM, Manoussakis MN. Salivary gland epithelial cell exosomes: A source of autoantigenic ribonucleoproteins. Arthritis Rheum 2005; 52: 15171521.

27. Pauley KM, Cha S, Chan EK. MicroRNA in autoimmunity and autoimmune diseases. J Autoimmun 2009; 32: 189194.

28. Gallo A, Tandon M, Alevizos I, Illei GG. The majority of microRNAs detectable in serum and saliva is concentrated in exosomes. PloS one 2012; 7: 1-5.

29. Michael A, Bajracharya SD, Yuen PS, Zhou $H$, Star RA,Illei GG, Alevizos I. Exosomes from human saliva as a source of microRNA biomarkers. Oral Dis 2010; 16 : 34-38.

30. Alevizos I, Alexander S, Turner RJ,Illei GG. MicroRNA expression profiles as biomarkers of minor salivary gland inflammation and dysfunction in Sjögren's syndrome. Arthritis Rheum 2011; 63: 535-544.

31. Keller S, Ridinger J, Rupp AK, Janssen JW, Altevogt $P$. Body fluid derived exosomes as a novel template for clinical diagnostics. J Transl Med 2011; 9: 86-94.

32. Reid G, Kirschner MB, van Zandwijk N. Circulating microRNAs: Association with disease and potential use as biomarkers. Crit Rev Oncol Hematol 2011; 80: 193208.

33. Byun JS, Hong SH, Choi JK, Jung JK, Lee HJ. Diagnostic profiling of salivary exosomal microRNAs in oral lichen planus patients. Oral Dis 2015; 21: 987-993.

34. Ma H, Wu Y, Yang H, Liu J, Dan H, Zeng X, Zhou Y, Jiang $L$, Chen $Q$. MicroRNAs in oral lichen planus and potential miRNA-mRNA pathogenesis with essential cytokines: a review. Oral Surg Oral Med Oral Pathol Oral Radiol 2016; 122: 164-173.

35. Ogawa $Y$, Miura $Y$, Harazono $A$, Kanai-Azuma $M$, Akimoto $Y$, Kawakami H, Yamaguchi T, Toda T, Endo T, Tsubuki M, Yanoshita R. Proteomic analysis of two types of exosomes in human whole saliva. Biol Pharm Bull 2011; 34: 13-23.

Trop J Pharm Res, March 2020; 19(3): 671 
36. Jemal A, Bray F, Center MM, Ferlay J, Ward E, Forman D. Global cancer statistics. CA Cancer J Clin 2011; 61: 69-90.

37. Sano D, Myers JN. Metastasis of squamous cell carcinoma of the oral tongue. Cancer Metast Rev 2007; 26: 645-662.

38. Kowalski LP, Sanabria A. Elective neck dissection in oral carcinoma: a critical review of the evidence. Acta Otorhinolaryngol Ital 2007; 27: 113-117.

39. Neville BW, Day TA. Oral cancer and precancerous lesions. CA Cancer J Clin 2002; 52: 195-215.

40. Zlotogorski-Hurvitz A, Dayan D, Chaushu G, Salo $T$, Vered M. Morphological and molecular features of oral fluid-derived exosomes: oral cancer patients versus healthy individuals. J Cancer Res Clin Oncol 2016; 142: 101-110.

41. Li L, Li C, Wang S, Wang Z, Jiang J, Wang W, Li X, Chen J, Liu K, Li C, Zhu G. Exosomes Derived from Hypoxic Oral Squamous Cell Carcinoma Cells Deliver miR-21 to Normoxic Cells to Elicit a Prometastatic Phenotype. Cancer Res 2016; 76: 1770-1780.

42. Liu T, Chen G, Sun D, Lei M, Li Y, Zhou C, Li X, Xue W, Wang $\mathrm{H}$, Liu $\mathrm{C}, \mathrm{Xu} \mathrm{J}$. Exosomes containing miR-21 transfer the characteristic of cisplatin resistance by targeting PTEN and PDCD4 in oral squamous cell carcinoma. Acta Biochim Biophys Sin 2017; 49: 808816.

43. Kawakubo-Yasukochi $T$, Morioka $M$, Hazekawa $M$, Yasukochi A, Nishinakagawa T, Ono K, Kawano S, Nakamura S, Nakashima M. miR-200c-3p spreads invasive capacity in human oral squamous cell carcinoma microenvironment. Mol Carcinog 2018; 57: 295-302.

44. Winck FV, Ribeiro ACP, Domingues RR, Ling LY, RiañoPachón DM, Rivera C, Brandão TB, Gouvea AF, Santos-Silva AR, Coletta RD, Leme AF. Insights into immune responses in oral cancer through proteomic analysis of saliva and salivary extracellular vesicles. Sci Rep 2015; 5: 16305-16317.

45. Lai RC, Yeo RWY, Tan KH, Lim SK. Exosomes for drug delivery - a novel application for the mesenchymal stem cell. Biotechnol Adv 2013; 31: 543-551.

46. Braicu C, Tomuleasa C, Monroig P, Cucuianu A, Berindan-Neagoe I, Calin GA. Exosomes as divine messengers: are they the Hermes of modern molecular oncology? Cell Death Differ 2015; 22: 34-45.

47. Ohno S, Takanashi M, Sudo K, Ueda S, Ishikawa A, Matsuyama N, Fujita K, Mizutani T, Ohgi T, Ochiya $T$,
Gotoh N. Systemically injected exosomes targeted to EGFR deliver antitumor microRNA to breast cancer cells. Mol Ther 2013; 21: 185-191.

48. Akao $Y$, lio $A$, Itoh $T$, Noguchi $S$, Itoh $Y$, Ohtsuki $Y$, Naoe T. Microvesicle-mediated RNA molecule delivery system using monocytes/macrophages. Mol Ther 2011; 19: 395-399.

49. Cho JA, Park H, Lim EH, Lee KW. Exosomes from breast cancer cells can convert adipose tissue-derived mesenchymal stem cells into myofibroblast-like cells. Int J Oncol 2012; 40: 130-138.

50. Tran T-H, Mattheolabakis G, Aldawsari H, Amiji M. Exosomes as nanocarriers for immunotherapy of cancer and inflammatory diseases. Clin Immunol 2015; 160: 4658.

51. Munich S, Sobo-Vujanovic A, Buchser WJ, Beer-Stolz D, Vujanovic NL. Dendritic cell exosomes directly kill tumor cells and activate natural killer cells via TNF superfamily ligands. Oncoimmunology 2012; 1: 1074-1083.

52. Delcayre A, Le JP. Exosomes as novel therapeutic nanodevices. Curr Opin Mol Ther 2006; 8: 31-38.

53. Alvarez-Erviti L, Seow Y, Yin H, Betts C, Lakhal S, Wood MJ. Delivery of SiRNA to the mouse brain by systemic injection of targeted exosomes. Nat Biotechnol 2011; 29: 341-345.

54. Kim SH, Bianco NR, Shufesky WJ, Morelli AE, Robbins $P D$. Effective treatment of inflammatory disease models with exosomes derived from dendritic cells genetically modified to express IL-4. J Immunol 2007; 179: 22422249.

55. Lai RC, Arslan F, Lee MM, Sze NS, Choo A, Chen TS, Salto-Tellez M, Timmers L, Lee CN, El Oakley RM, Pasterkamp G. Exosome secreted by MSC reduces myocardial ischemia/reperfusion injury. Stem Cell Res 2010; 4: 214-222.

56. Ranghino A, Cantaluppi V, Grange C, Vitillo L, Fop F, Biancone L, Deregibus MC, Tetta C, Segoloni GP, Camussi G. Endothelial progenitor cell-derived microvesicles improve neovascularization in a murine model of hindlimb ischemia. Int J Immunopathol Pharmacol 2012; 25: 75-85.

57. Bruno S, Grange C, Deregibus MC, Calogero RA, Saviozzi S, Collino F, Morando L, Falda M, Bussolati B, Tetta C, Camussi G. Mesenchymal stem cell-derived microvesicles protect against acute tubular injury. J Am Soc Nephrol 2009; 20: 1053-1067.

58. Hadavand M, Hasni S. Exosomal biomarkers in oral diseases. Oral Dis 2019; 25: 10-15. 